\title{
Arbor
}

\section{La gran señora de la escena. La actriz como gran representante del dramatismo humano}

\author{
M. ${ }^{a}$ Jesús Valdés
}

Arbor CLXVIII, 663 (Marzo 2001), 389-394 pp.

Mis queridos amigos:

No sé si me conocéis todos. He de advertiros que no soy una actriz popular, soy eso, solamente una actriz y una mujer privilegiada.

Antes de escribiros esta carta comienzo a repasar los diversos caminos de mi vida, más bien, diría yo, de mis tres vidas - otro privilegio- y en esos caminos y en esos rincones donde tanto yo, como vosotros en los vuestros, sabemos de sinsabores, de desamores, de alegrías, de amigos que se nos quedaron un poco lejos, de otros que llegaron a seguir dando sentido a nuestras vidas.

No os quiero cansar. Sí, soy una actriz. No sé bien ni como ni por qué me encontré un día a los cuatro años sobre un escenario. El escenario de $\mathrm{mi}$ recordado colegio Salesiano y desde entonces la fantasía de los primeros cuentos, las representaciones donde solían llevarme mis padres (amantes del teatro), todo aquel mundo mágico del que no me separé jamas pese a las objeciones lógicas de que aquello de ser «ARTISTA» no estaba bien visto. Yo iba para archivera bibliotecaria que era algo mucho más seguro y por lo visto, era una buena estudiante.

Me escapaba desde mi Instituto «Lope de Vega» al Real Conservatorio donde conocí unos maestros extraordinarios como Don Ricardo Calvo, Doña Carmen Seco, Don Fernando Fernández de Córdoba (para fomentar una buena dicción) y Don José Franco.

De aquella época y ya integrada en el Teatro Español Universitario de Madrid conocí a uno de los mejores directores del Teatro español Modesto Higueras, hoy casi olvidado por el paso del tiempo tan cruel a veces. 
Me emociono ante su recuerdo de aquellos años juveniles donde eramos capaces de representar desde «En Flandes se ha puesto el sol» a la «Prudencia en la Mujer» de Tirso, desde «Un día en la gloria» de Ruiz Iriarte a «Dios con Nosotros» de Vicente Escrivá y Armando Ocano.

Esta última función - otro privilegio- ya que fue dirigida por Cayetano Luca de Tena, otro nombre insigne al que debo muchos exitos en el Teatro Español de Madrid y que él supo dirigir en una de las décadas más brillantes del Español.

Fue demasiado sencillo todo, yo misma no me lo podía creer..., Luca de Tena me ofrecía aquella noche del Teatro Lara, un Contrato para el Español ya como primera actriz joven.

Cuando llegué a casa casi con lágrimas en los ojos y se lo dije a mis padres esperando ver en sus caras reflejada la emoción que yo tenía, me encontré con una nueva desilusión: ¿Y tu carrera?... Yo les respondí que la haría compatible con el teatro.

No pudo ser así, pero mis padres terminaron entendiendo que el teatro era mi autentica vocación.

Se levantó el telón con la obra de Lope «El Villano en su rincón» y a los pocos meses supe que me habían premiado con la Medalla de Oro del Circulo de Bellas Artes. Después «Historia de una escalera»: el descubrimiento de un nuevo autor que un día sería universal Antonio Buero Vallejo. Y por fin mi «INES» de Don Juan Tenorio. No sé si alguien recordará aquella noche y aquel exito, pero puedo asegurar que aquella Doña Inés nueva, con pelo suelto, sin tocas y tan bien dirigida por Cayetano con escenografía de Emilio Burgos, marcó para siempre mi vida de actriz.

En el «Alcalde de Zalamea» conocí a la actriz Dolores del Río, a Joan Fontaine, al maestro italiano Antonioni con Vitorio Gasman y a tantísimas personalidades inolvidables.

Se sucedieron en mi lista interpretativa: «Ruy Blas» de Victor Hugo, «Condenados» de Luis Sánchez Carreño, «El abanico de Goldoni» y tantas otras..., con cual de ellas me sentía más contenta? No lo sé; En los actores y actrices la ultima representación es la que más se quiere.

Surge un nuevo contrato para el teatro María Guerrero dirigido por Alfredo Marquerie, uno de mis mas recordados e ilustres críticos. Allí voy a representar una preciosa Comedia del actor-autor Peter Ustinov titulada «El amor de los 4 Coroneles».

Después llegó «El cuarto de estar» de Graham Greene y por fin decidí formar mi propia compañía dirigida por aquel famoso director y entrañable amigo que era José Luis Alonso. Fueron unas temporadas brillantes acompañada de los mejores actores jóvenes del momento: Francisco Valladares, Jesús Puente, María Luisa Ponte, Agustín González, 


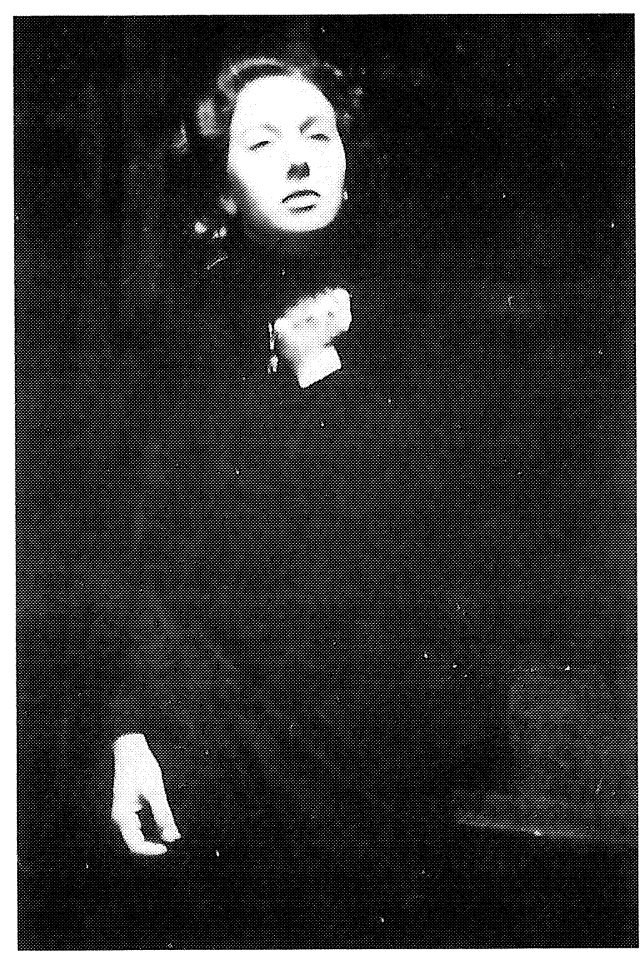

«El cuarto de estar».

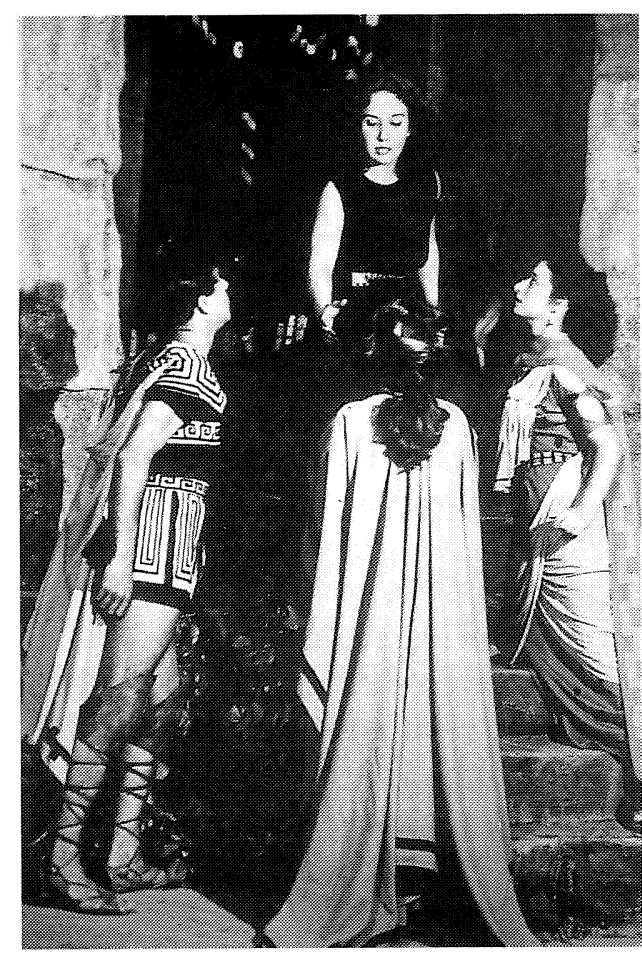

«Electra», de Sófocles, 1955.

Mariano Asquerino, José $\mathrm{M}^{\mathrm{a}}$ Mompin, Julieta Serrano, Mari Carmen Prendes, Alicia Hermida...¡Dios Mío, cuantas ilusiones y cuantos recuerdos que se quedaron tan lejos!...

«Medida por Medida», «La Fierecilla Domada», «El Mensaje» de Salom, "La Feria de Cuernicabra». Si de algo me precio, mis amigos queridos, es de haber tratado de aportar al teatro todo mi esfuerzo y el de mis compañeros apostando siempre por un teatro de calidad.Y de pronto... un cambio radical en mi vida. Conozco a alguien en el camino que hace que mis planes sean otros absolutamente diferentes y decido ante ese amor abandonar lo que hasta entonces había sido mi obsesión y mi lucha, mi vocación autentica y me caso decidida a olvidar todo aquello que me había hecho tan feliz, para sustituirlo por otra felicidad nueva y desconocida que nada tenía que ver con el teatro. Decido dedicarme a aquel hombre que todo lo merecía y a unos hijos que llegaron después y que son lo mejor de mi vida.

No pensé volver jamás a pisar un escenario. Lo que hice lo realicé voluntariamente sin ser mediatizada por nadie y con la alegría que implicaba un nuevo deber en mi vida: Mi marido y mis hijos. 
Así se pasaron los años iiVeintitrés nada menos!!

Yo no podía pensar que un día tendría que quedarme sola, la ausencia de aquel ser querido que se había marchado a un largo viaje del que tardaría seguramente siglos en volver. Así con esa nostalgia dolorosa se sucedieron algunos años más hasta que un día vuelve a sonar el teléfono reiterativamente (era la voz del productor y amigo Juanjo Seoane) quien no cejaba en su empeño de que algún día tendría que volver al teatro. Mis respuestas eran siempre negativas y otro día de esos que amanecen con la sensación de que algo va a ocurrir, recibo una llamada de Adolfo Marsillach invitándome a unas clases magistrales, compartidas con otros compañeros.

Rápidamente y sin dudarlo, sin saber por qué le respondí que sí. El contacto

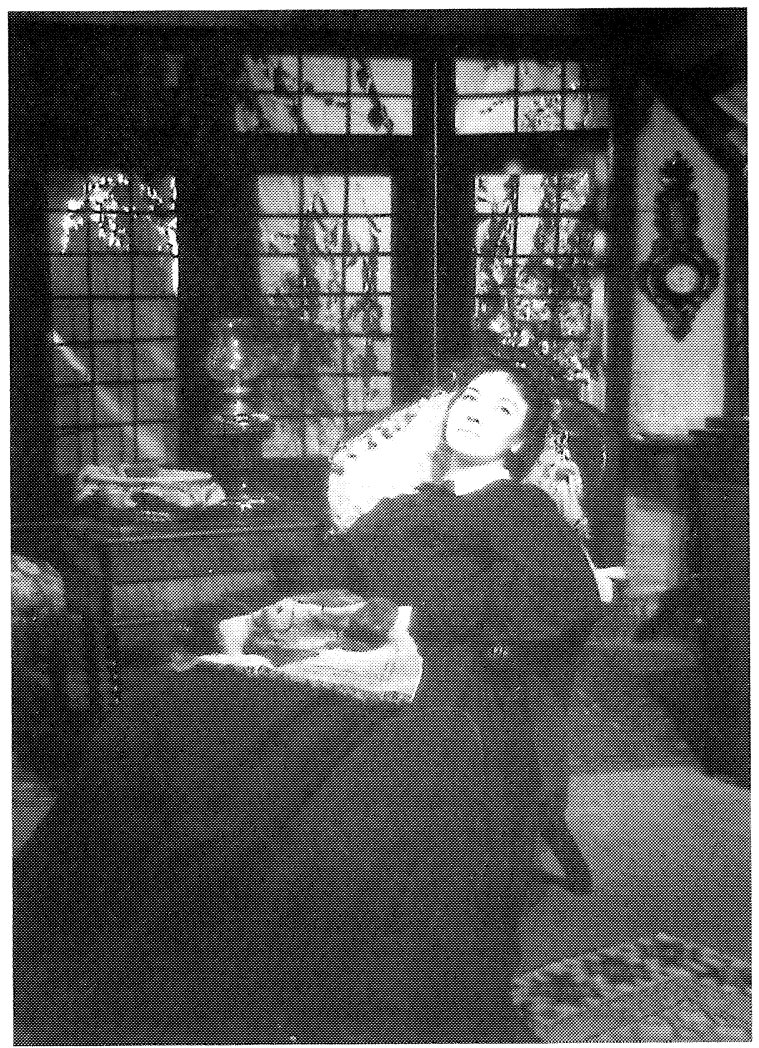

«La hora de la fantasía». Teatro Infanta Isabel. Su último triunfo. Cuando el público madrileño aplaudió, a María Jesús Valdés por su labor en "La hora de la fantasía», no podía sospechar que era aquélla la última vez, María Jesús está cansada de muchas circunstancias que juegan en el teatro. Y pasada su brillantísima "hora de la fantasía" -varios años de éxitos ininterrumpios-deja la escena. con los jóvenes me convenció y me conmovió el pensar que de nuevo iba a encontrarme con José Luis Alonso.. iijuntos otra vez!! después de tantos años. Me parecía todo nuevo y maravillosos en la nueva escuela creada por Marsillach para su teatro clásico. De nuevo el teléfono y aquella noche se decidió mi suerte. Me volvió a insistir Juanjo Seoane con una pregunta: Maria Jesús ¿por que no me das un nombre para Lady Macbeth?, Juanjo hay actrices maravillosas en España... ¿Que te parecería Maria Jesús Valdés? Después de un silencio nos echamos a reir los dos.-Pues mira sí- de acuerdo, está bien, hablaremos con Nuria Espert para dirigirlo y con Paco Rabal.

No pudo realizarse este sueño pero yo había quedado ya enredada en el teatro de nuevo y seguramente para siempre. 


\section{La gran señora de la escena}

Estrenamos «La Dama del Alba» de Casona. Iba a dirigirla un muchacho joven, desconocido para mi y con mucho talento, asesorando artísticamente Maruja López. Quien me iba a decir que aquel chico mezcla de niño ingenuo y a la vez con un temperamento increíble me llegaría a dirigir de

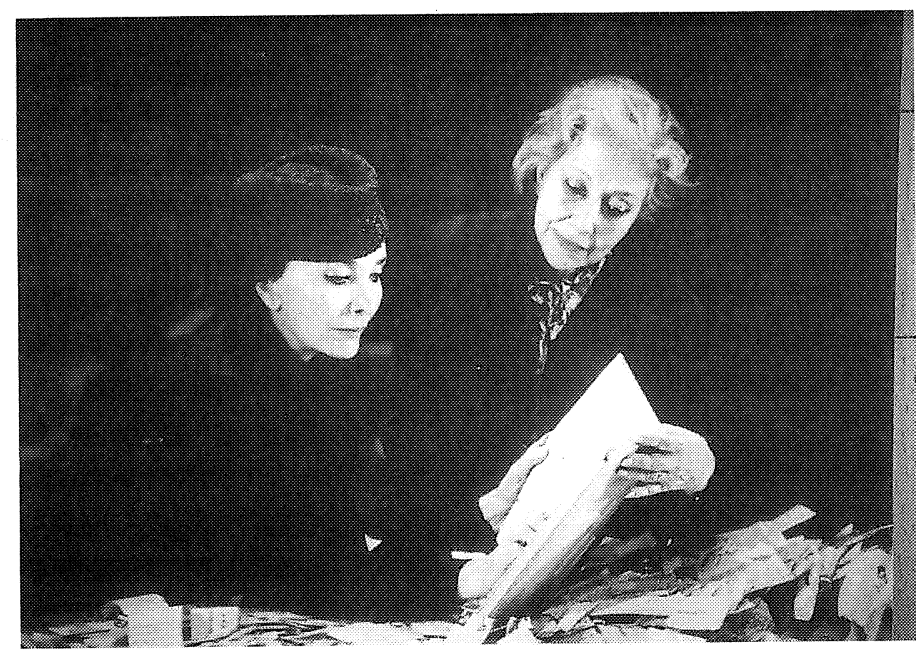

«El cerco de Leningrado», de Sanchis Sinisterra. nuevo ocupando el puesto de Director del Centro Dramático Nacional en «La Visita de la Vieja Dama» de Frederich Durrenmat.

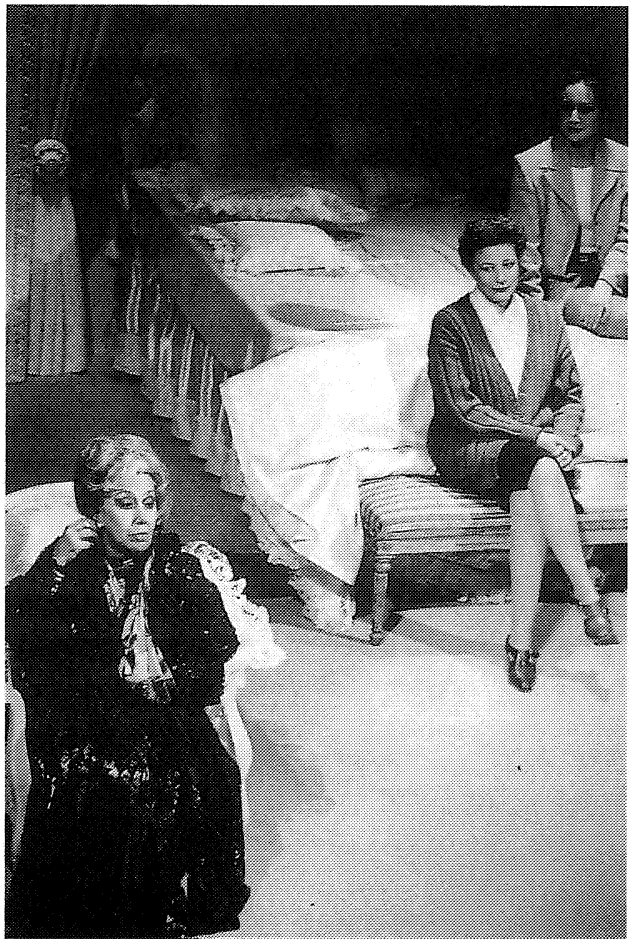

«Tres mujeres altas» de Edward Albee.

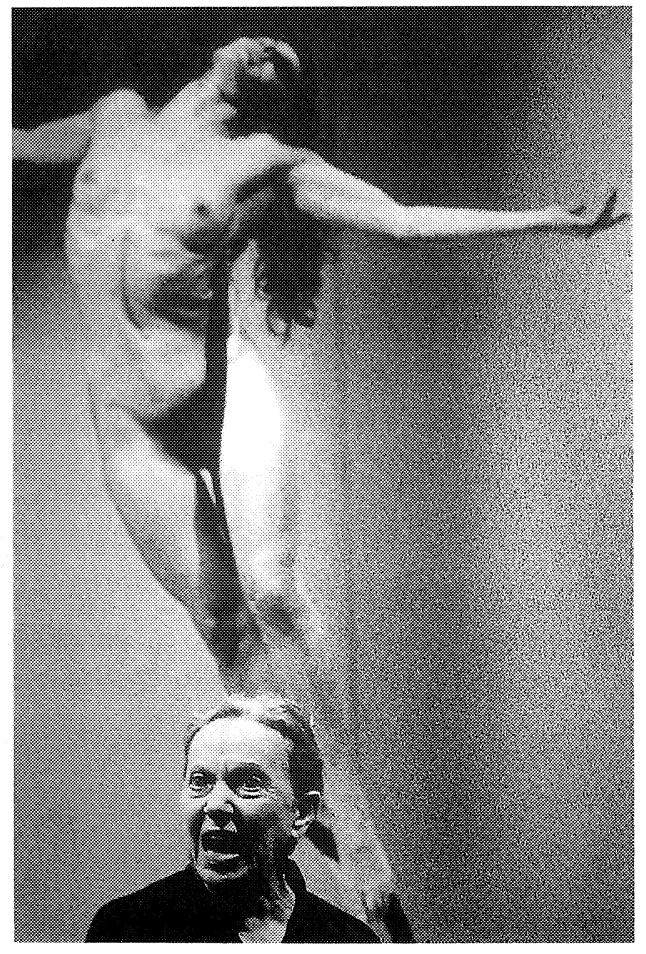

"La casa de Bernarda Alba», de Federico García Lorca 


\section{M. ${ }^{a}$ Jesús Valdés}

394

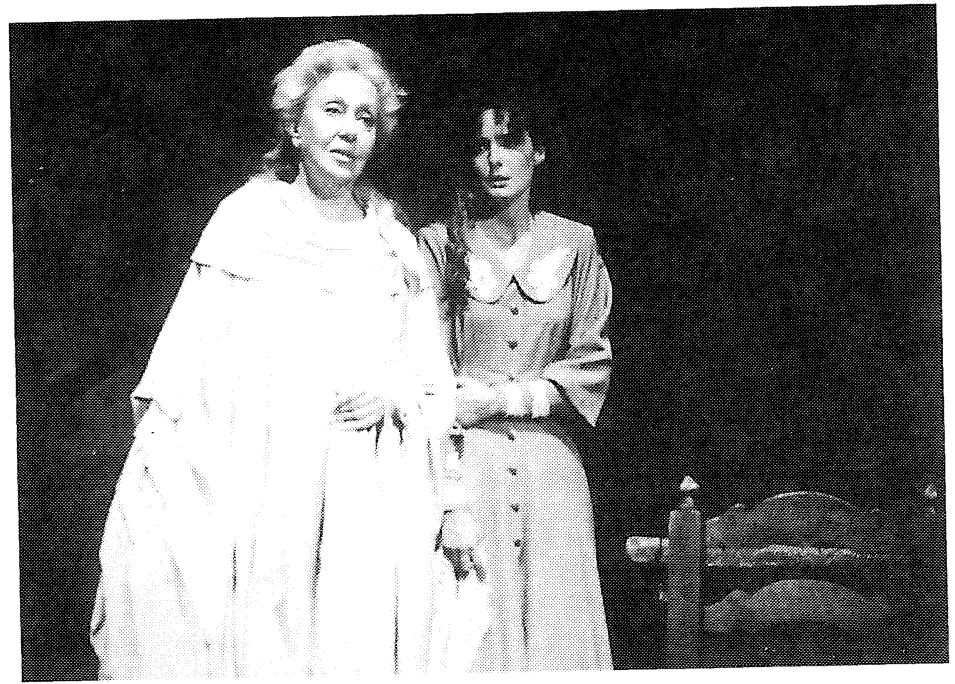

Amigos míos perdonadme si me he extendido demasiado. No me gusta hacerlo $\mathrm{y}$ prefiero ser concisa en mis cartas. No sé por qué con vosotros no me ha ocurrido así. Estoy relajada y muy a gusto escribiendo y abriéndoos el alma.

"La Dama del Alba» de Alejandro Casona.

Ya llevo casi una década desde mi vuelta y no he parado: "La Dama del Alba», un homenaje a Tono en "La Vida es Sueño», "Tres Mujeres Altas» de Edward Albee, «El cerco de Leningrado» de Sanchis Sinisterra junto a Nuria Espert, «Una noche con los clásicos» con Amparo Rivelles y Adolfo Marsillach, «La casa de Bernarda Alba» dirigida por Calixto Bieito, «El Gran Teatro del Mundo» por José Tamayo, mi «Ultima Visita» y... entre tanto ponencias, premios, recitales...ya os lo dije, soy una mujer privilegiada.

Un abrazo grande a cada uno.

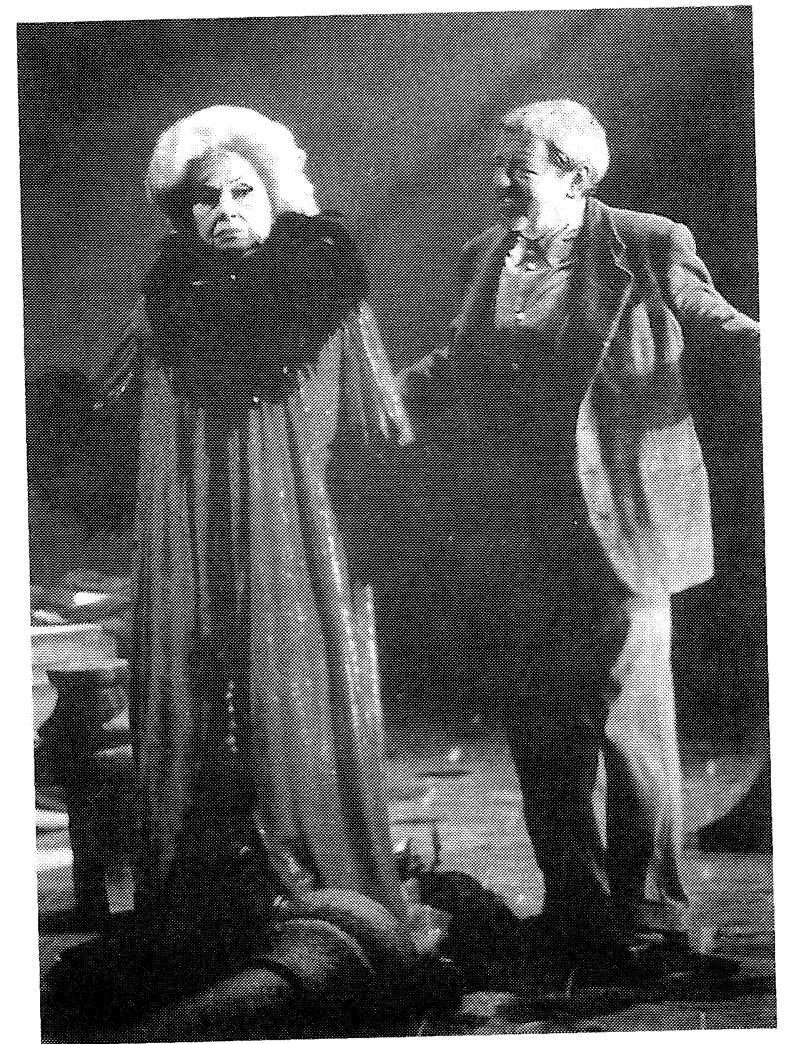

«La Visita de la Vieja Dama» de Frederich Durrenmat. 